\title{
Case Report \\ Coexisting Situs Inversus Totalis and Immune Thrombocytopenic Purpura
}

\author{
Kemal Gundogdu, ${ }^{1}$ Fatih Altintoprak, ${ }^{2}$ Mustafa Yener Uzunoğlu, ${ }^{1}$ Enis Dikicier, \\ İsmail Zengin, ${ }^{1}$ and Orhan Yağmurkaya ${ }^{1}$ \\ ${ }^{1}$ Department of General Surgery, Sakarya University Research and Educational Hospital, Sakarya, Turkey \\ ${ }^{2}$ Department of General Surgery, Sakarya University Faculty of Medicine, Sakarya, Turkey
}

Correspondence should be addressed to Fatih Altintoprak; fatihaltintoprak@yahoo.com

Received 3 December 2015; Accepted 12 January 2016

Academic Editor: Christoph Schmitz

Copyright ( $) 2016$ Kemal Gundogdu et al. This is an open access article distributed under the Creative Commons Attribution License, which permits unrestricted use, distribution, and reproduction in any medium, provided the original work is properly cited.

Situs inversus totalis is a rare congenital abnormality with mirror symmetry of mediastinal and abdominal organs. Immune thrombocytopenic purpura is an autoimmune disease with destruction of thrombocytes. This paper is presentation of surgical approach to a case with coexistence of these two conditions.

\section{Introduction}

Chronic immune thrombocytopenic purpura (ITP) is an autoimmune disease characterized by an immune response to thrombocyte membrane antigens. ITP is generally treated with surgery and steroids [1]. Situs inversus totalis is a rare congenital abnormality in which all of the mediastinal and abdominal organs are transposed to mirror symmetry of the normal anatomy. This paper reports the coexistence of these two rare conditions.

\section{Case Presentation}

A 35-year-old woman was referred to our clinic with a diagnosis of ITP resistant to medical treatment in whom a splenectomy was indicated. For 7 years, she had been treated regularly with $1 \mathrm{mg} / \mathrm{kg} /$ day methylprednisolone and episodic intravenous immunoglobulin (IVIG) in the hematology clinic and had persistent thrombocytopenia of 3,000$60,000 / \mathrm{mm}^{3}$, ongoing menorrhagia, and ecchymosis. The patient had two healthy births after IVIG treatment. Preoperatively, dextrocardia was detected on an electrocardiogram and thoracoabdominal computed tomography (CT) showed situs inversus totalis. In addition to mirror imaging of the normal anatomic locations of all organs, the spleen measured
$13 \times 6 \mathrm{~cm}$ and there was a $1.5 \mathrm{~cm}$ accessory spleen in the right upper quadrant (Figure 1). Although no abnormalities were seen in the head and body of the pancreas, no pancreatic tail was seen. In other words, the pancreas had not crossed over to the right side of the superior mesenteric vascular axis and there was no pancreatic tissue near the splenic hilum (Figure 2). The patient underwent a laparoscopic splenectomy (Figure 3) with no complications or adverse events following surgery. She was discharged on the third postoperative day with thrombocyte count of $155,000 / \mathrm{mm}^{3}$.

\section{Discussion}

Immune (idiopathic) thrombocytopenic purpura is an autoimmune disease characterized by the destruction of thrombocytes or suppression of their production as a result of an immune reaction with thrombocyte membrane autoantigens [1]. Therapy is required when the thrombocyte count falls below $20,000 / \mathrm{mm}^{3}$ or if there are symptoms such as mucosal or vaginal hemorrhage when the count is in the range $20,000-50,000 / \mathrm{mm}^{3}$. In the event of nonresponse to medical therapy, the alternative therapy is splenectomy [2]. The treatment success rate after splenectomy ranges within $50-70 \%$. Accessory spleens are found in $15 \%$ of the general population and should be detected in ITP patients when a 


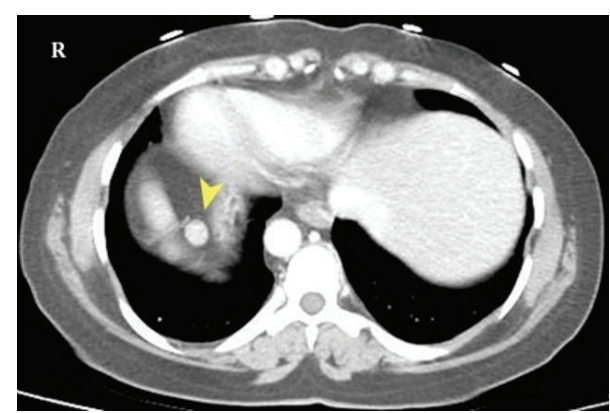

(a)

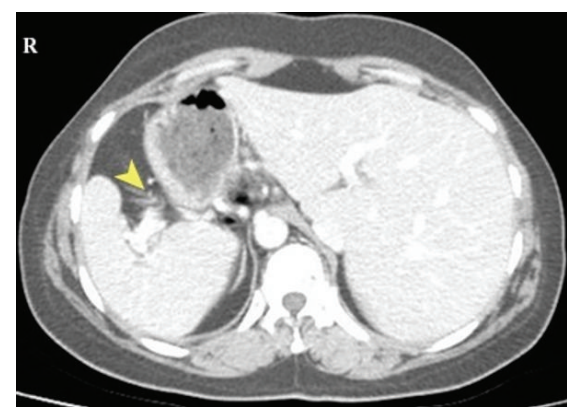

(b)

FIGURE 1: Abdomen CT; mirror view of intra-abdominal organs due to situs inversus, accessory spleen (arrow head (a)), and no pancreatic tissue in splenic hilum (arrow head (b)).

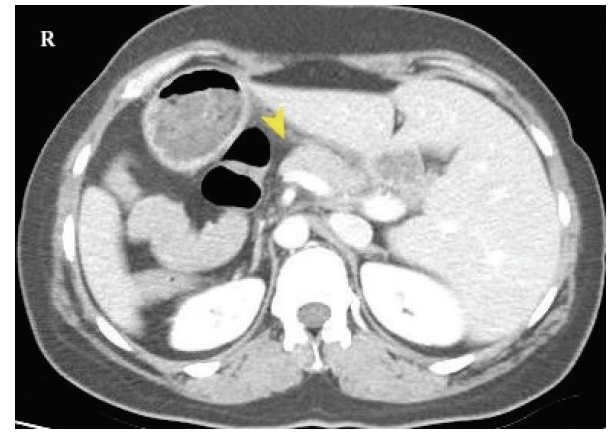

(a)

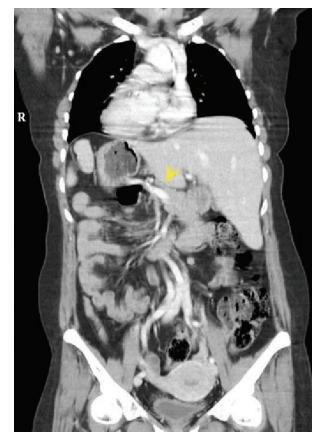

(b)

FIGURE 2: Abdomen CT; pancreatic tissue ends by bounds of superior mesenteric vein axis.

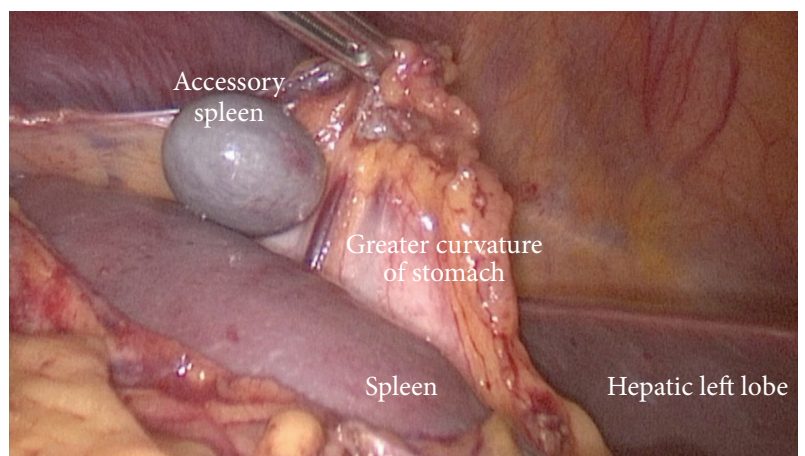

FIGURE 3: Intraoperative view; accessory spleen.

splenectomy is planned to prevent incomplete removal of spleen tissue [3]. In our case, an accessory spleen was detected on preoperative CT and excised.

Situs inversus totalis is a rare condition with an incidence of 1/10,000 characterized by transposed organs and systems to mirror symmetry instead of the normal anatomy [4]. It is thought that an autosomal recessive genetic predisposition characterized as a defect on the long $\operatorname{arm}(\mathrm{q})$ of the 14th chromosome is responsible for organ transposition. Coexistence of SIT and various congenital abnormalities has been reported $[5,6]$. The absence of a pancreatic tail in our case corresponded with the literature. In rare reported cases, patients with SIT undergo surgery for various indications. Anatomic congenital abnormalities result in surgeons practicing in unfamiliar territory, with undesirable outcomes if the surgeon is not aware of an abnormality, such as in emergency interventions. The pancreatic abnormality in our case did not cause any problems because it was identified preoperatively. Furthermore, the absence of pancreatic tissue near the splenic hilum facilitated isolation of the splenic vessels, eliminated the risk of pancreatic injury, and facilitated perioperative movements, contributing to an uneventful operation.

\section{Conclusion}

The coexistence of situs inversus totalis and ITP is very rare. We believe that a detailed radiological examination is very important for detecting accompanying anatomic abnormalities when surgical intervention is planned.

\section{Conflict of Interests}

The authors declare that they have no conflict of interests.

\section{References}

[1] B. S. Flores-Chang, C. E. Arias-Morales, F. G. Wadskier, S. Gupta, and N. Stoicea, "Immune thrombocytopenic purpura 
secondary to cytomegalovirus infection: a case report," Frontiers in Medicine, vol. 2, article 79, 2015.

[2] R. Vecchio, E. Cacciola, R. R. Cacciola, F. Palazzo, C. Rinzivillo, and R. Giustolisi, "Predictive factors of response to splenectomy in adult chronic idiopathic thrombocytopenic purpura," International Surgery, vol. 85, no. 3, pp. 252-256, 2000.

[3] K. J. Mortelé, B. Mortelé, and S. G. Silverman, "CT features of the accessory spleen," American Journal of Roentgenology, vol. 183, no. 6, pp. 1653-1657, 2004.

[4] Y. Han, T. Liu, X. Qiu et al., "PEComa of the uterus with coexistence of situs inversus totalis, a case report and literature review, Diagnostic Pathology, vol. 10, no. 1, article 142, 2015.

[5] A. J. Shapiro, S. D. Davis, T. Ferkol et al., "Laterality defects other than situs inversus totalis in primary ciliary dyskinesia: insights into situs ambiguus and heterotaxy," Chest, vol. 146, no. 5, pp. 1176-1186, 2014.

[6] C. Bergmann, M. Fliegauf, N. O. Brüchle et al., "Loss of nephrocystin-3 function can cause embryonic lethality, meckel-gruber-like syndrome, situs inversus, and renalhepatic-pancreatic dysplasia," The American Journal of Human Genetics, vol. 82, no. 4, pp. 959-970, 2008. 


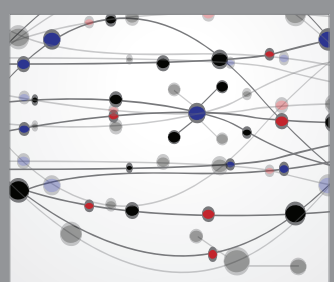

The Scientific World Journal
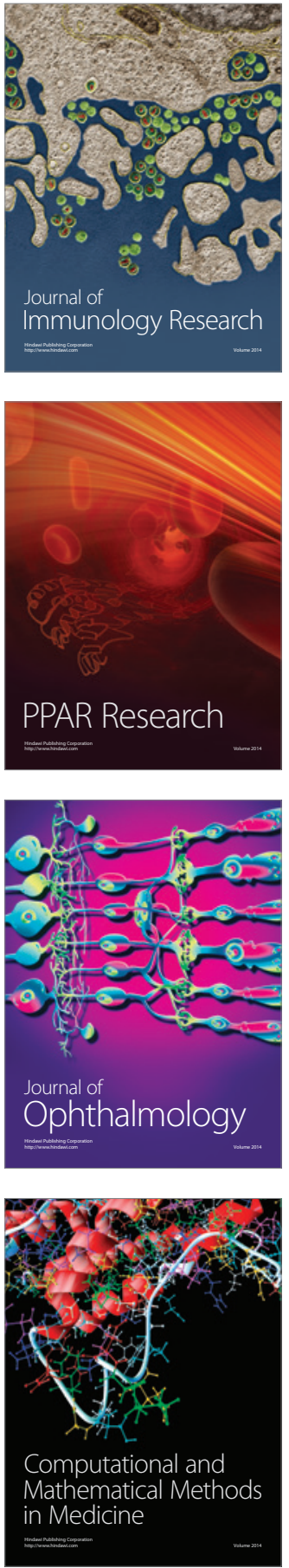

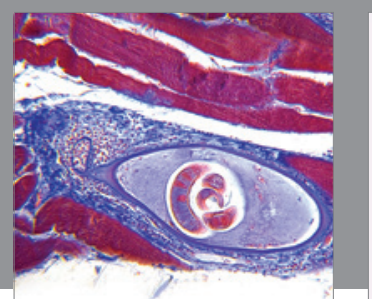

Gastroenterology Research and Practice

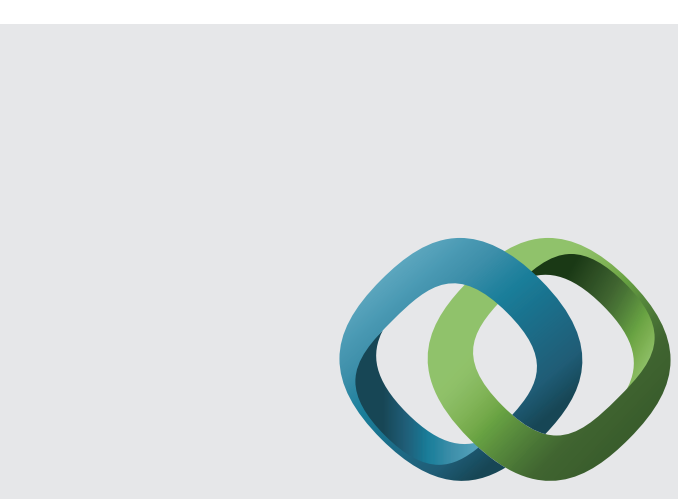

\section{Hindawi}

Submit your manuscripts at

http://www.hindawi.com
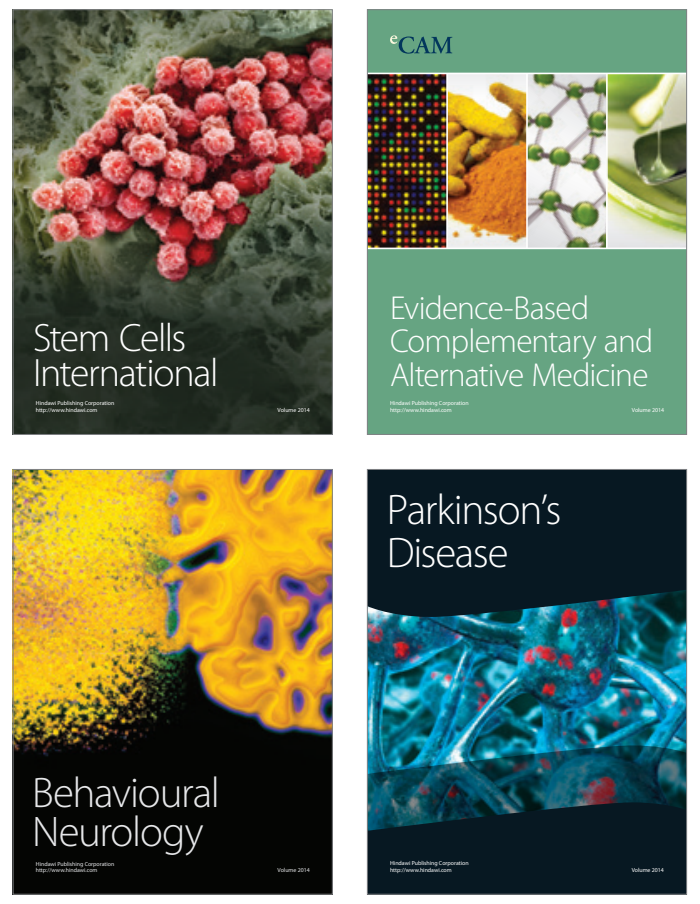
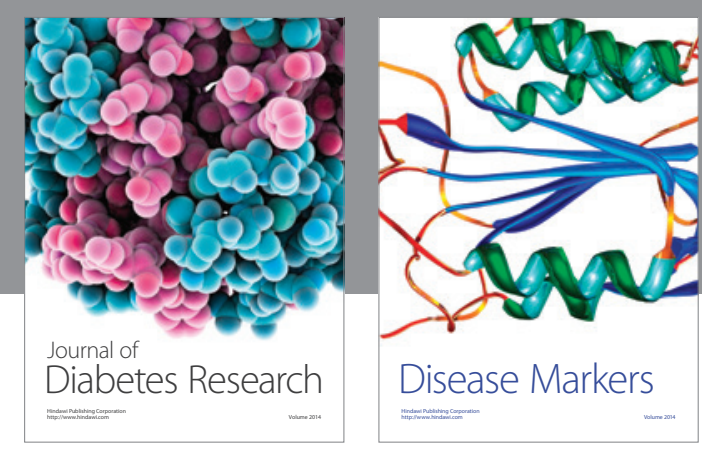

Disease Markers
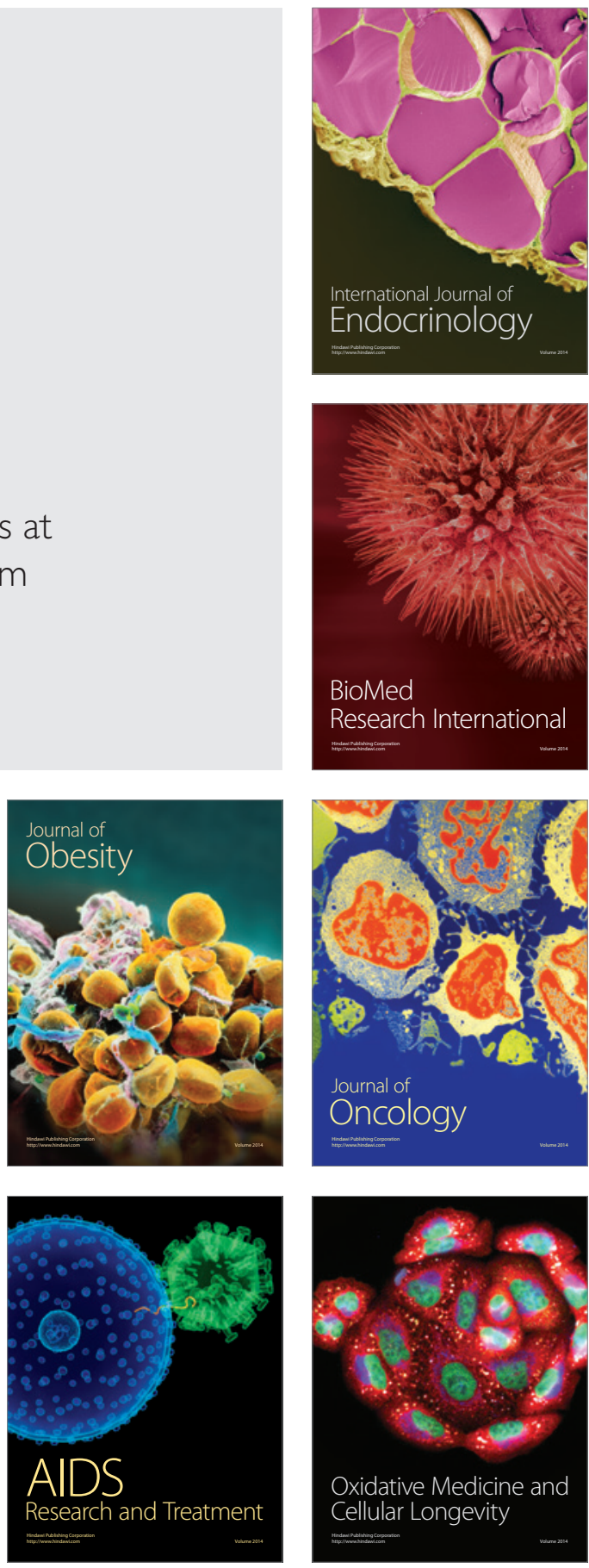